\title{
Intramural myomas: to treat or not to treat
}

This article was published in the following Dove Press journal:

International Journal of Women's Health

17 May 2016

Number of times this article has been viewed

\author{
Mayra J Thompson \\ Bruce R Carr \\ Department of Obstetrics and \\ Gynecology, University of Texas \\ Southwestern Medical Center, Dallas, \\ TX, USA
}

\begin{abstract}
A debate among gynecologic and reproductive surgeons is whether or not there is a clinical need to treat all intramural myomas. Considerations include myoma size and number, ability to access them, whether or not they compromise the endometrium, and treatment effect on gynecologic, reproductive, and obstetric outcomes. We conducted a detailed study regarding intramural myomas, their prevalence in subject populations, the imaging methods used to detect them, their growth rate, their suspected adverse effects on gynecologic, fertility, and obstetric outcomes, and the effectiveness of various treatment methods. The growing body of evidence reported in the literature supports the need to manage intramural myomas and to treat them appropriately.
\end{abstract}

Keywords: intramural myomas, myoma therapies, uterine artery embolization, myomectomy, radiofrequency volumetric thermal ablation, magnetic resonance-guided focused ultrasound

\section{Overview of uterine myomas}

Uterine myomas have been classified according to their general uterine position: submucous, intramural, and subserosal. Munro et al ${ }^{1}$ further classified myomas into nine types according to the degree of intracavitary and serosal distortion. Although the International Federation of Gynecology and Obstetrics classification has allowed the researchers, imaging specialists, and surgeons specificity when identifying and treating myomas, the older classification (submucous, intramural, and subserosal) persists in the literature. The focus of our research is intramural myomas, primarily the International Federation of Gynecology and Obstetrics types 3 and 4 (Figure 1).

Depending on the number, sizes, and types of myomas, the age of the patient, her desire for uterine conservation, her workplace, personal environment, and lifestyle, and her presenting symptoms, treatment can take any of several medical and surgical courses. ${ }^{2}$ Treatment goals are long-term reduction in myoma volume and reduction or elimination of symptoms with minimal side effects. Although medical therapies have been used to reduce bleeding and/or myoma volume, they are not without limitations and side effects, and medical therapies are often followed by surgical or interventional management. The decision to manage treatment by surgical or interventional means must take into account myoma size and number, proximity to the endometrium, ability to access and treat them, potential adverse consequences, as well as patient preference. Pretreatment assessment by ultrasound or magnetic resonance imaging (MRI), as well as evaluation of comorbidities may also preclude a patient from undergoing certain procedures.

\section{Intramural myomas}

Intramural myomas are the most prevalent of all the leiomyomas. Two-dimensional transvaginal sonography detected a $58 \%-79 \%$ occurrence of intramural myomas 


\begin{tabular}{|c|c|c|c|}
\hline \multirow{11}{*}{$\begin{array}{l}\text { Leiomyoma } \\
\text { subclassification } \\
\text { system }\end{array}$} & \multirow[t]{3}{*}{ SM - Submucosal } & 0 & Pedunculated intracavitary \\
\hline & & 1 & $<50 \%$ intramural \\
\hline & & 2 & $\geq 50 \%$ intramural \\
\hline & \multirow[t]{6}{*}{ O-Other } & 3 & Contacts endometrium; $100 \%$ intramural \\
\hline & & 4 & Intramural \\
\hline & & 5 & Subserosal $\geq 50 \%$ intramural \\
\hline & & 6 & Subserosal $<50 \%$ intramural \\
\hline & & 7 & Subserosal pedunculated \\
\hline & & 8 & Other (specify eg, cervical, parasitic) \\
\hline & \multirow{2}{*}{$\begin{array}{l}\text { Hybrid } \\
\text { leiomyomas } \\
\text { (impact both } \\
\text { endometrium } \\
\text { and serosa) }\end{array}$} & \multicolumn{2}{|c|}{$\begin{array}{l}\text { Two numbers are listed separated by a hypen. By convention, the first } \\
\text { refers to the relationship with the endometrium, while the second refers to } \\
\text { the relationship to the serosa. One example is given below }\end{array}$} \\
\hline & & $2-5$ & $\begin{array}{l}\text { Submucosal and subserosal, each with less } \\
\text { than half the diameter in the endometerial } \\
\text { and peritoneal cavities, respectively }\end{array}$ \\
\hline
\end{tabular}

Figure I FIGO leiomyoma subclassification system.

Note: Reprinted from Int J Gynaecol Obstet. Vol I I3(I). Munro MG, Critchley HO, Broder MS, Fraser IS, FIGO Working Group on Menstrual Disorders. FIGO classification system (PALM-COEIN) for causes of abnormal uterine bleeding in nongravid women of reproductive age. Pages 3-13. Copyright 20I I, with permission from Elsevier.' Abbreviation: FIGO, International Federation of Gynecology and Obstetrics.

among study populations with observable myomas. ${ }^{3,4}$ MRI and laparoscopic ultrasound (LUS) are also used for myoma detection. In a multicenter retrospective study involving two-dimensional transvaginal sonography, MRI, and LUS, intramural myomas comprised $58 \%$ of all myomas imaged, regardless of the imaging method used. ${ }^{3}$

Myomas have a median growth rate of $35.2 \%$ by volume per year, and small $(<2 \mathrm{~cm})$ myomas grow significantly faster than do larger ones. ${ }^{5,6}$ Mavrelos et al ${ }^{5}$ detected a higher yearly volumetric increase of intramural myomas (53.2\%) compared to either subserosal or submucous myomas: $25.1 \%$ and $22.8 \%$, respectively. The literature provides conflicting or inadequately designed studies of the negative effects of intramurals..$^{7-16}$ The heterogeneous nature of intramural myomas (in terms of their relationship to the endometrial cavity, their size, and whether they occur as single or multiple tumors) and the conflicting diagnoses of what constitutes an intramural myoma illustrate the difficulty of the research.

In a prospective trial, Yoshino et $\mathrm{al}^{7}$ studied the increased frequency of uterine peristalsis in a group of infertile women who had intramural myomas, but no submucous myomas and no other infertility factors. The authors separated the women into two groups: one exhibiting low-frequency peristalsis $(<2$ times $/ 3$ minutes) during the midluteal phase and the other exhibiting higher-frequency peristalsis ( $\geq 2$ times/ 3 minutes). There were no significant differences in the two groups in terms of presence of endometriosis, distortion of the endometrial cavity, and number and size of intramural myomas. Less than half of the study subjects exhibited high-frequency peristalsis, none of whom achieved pregnancy, whereas $34 \%$ of the low-frequency group achieved pregnancy $(P<0.005)$. The authors suggest that abnormal uterine peristalsis in the presence of intramural fibroids may compromise pregnancy rates. Yan et al ${ }^{8}$ retrospectively investigated the effect that intramural myomas not distorting the endometrial cavity have on the outcome of in vitro fertilization treatment. Although such myomas did not affect in vitro fertilization/intracytoplasmic sperm injection outcomes, intramural myomas $>2.85 \mathrm{~cm}$ significantly compromised live birth rate $(P=0.043)$.

Another prospective study was undertaken to analyze the effects of the distance between small $(\leq 4 \mathrm{~cm})$ intramural uterine myomas and the endometrium on the outcomes of embryo transfer. ${ }^{9}$ The two groups of study subjects comprised infertile women with small intramural myomas $(n=117)$ and a control group of infertile women without uterine myomas $(\mathrm{n}=117)$. Outcomes were studied for distances from $\leq 1$ to $>3 \mathrm{~mm}$, with no myomas contacting or distorting the endometrium. The implantation rate (31.91\%) and live birth rate $(33.33 \%)$ were significantly lower and the spontaneous miscarriage rate $(20.37 \%)$ was significantly higher for the myoma group than for the control group (45.67\%, 52.14\%, and $7.35 \%$, respectively) (all, $P<0.05$ ).

In addition, histology and biochemical activity of individual myomas and their effects on the endometrium need continued in-depth study. ${ }^{10}$ Tinelli et a ${ }^{11}$ reported on their analysis of uterine myoma pseudocapsule thickness and histology based on earlier findings by Wei et al ${ }^{12}$ 
that the most biologically active area of a myoma is its pseudocapsule. Tinelli et $\mathrm{al}^{13}$ found that intramural myomas near the endometrial cavity were considerably thicker with physiologically active neuropeptides and neurotransmitters. The authors suggested that uterine myomas might best be managed based on immunohistochemical studies of myoma pseudocapsules.

Some authors have expressed reluctance to support treatment of intramural myomas in subfertile women. Cited reasons include lack of sufficient evidence and poorly designed trials, insufficient studies supporting or refuting the clinical benefits of treatment of non-cavity-distorting intramural myomas, and the inherent surgical complications and required expertise in the treatment of intramural myomas. ${ }^{14-17}$

\section{Uterine-conserving therapies for the treatment of intramural myomas}

\section{Myomectomy}

Myomectomy has been the mainstay treatment of symptomatic leiomyomas in women seeking uterine-conserving therapy and conservation and improvement in reproductive outcomes. Depending on the target myomas and the surgeon's preference and expertise, myomectomy approaches include hysteroscopic, laparoscopic, robotic-assisted laparoscopic, and laparotomic, the latter involving direct palpation of the uterus. Hysteroscopic myomectomy is reserved for treatment of submucous types 0,1 , and 2 myomas - the latter excised only if $<4 \mathrm{~cm}$ in greatest diameter and only by surgeons with advanced hysteroscopic technique and experience. ${ }^{16}$ Intramural myomas are more readily treated at laparotomy through a low transverse incision ${ }^{14}$ or at conventional laparoscopy or robotic-assisted laparoscopy. Careful palpation helps the surgeon to target hard-to-reach intramural fibroids during the open procedure. ${ }^{14}$ However, palpation of the uterus has limitations. In a prospective study evaluating LUS, surgeons performed the laparotomic procedure on women diagnosed preoperatively with symptomatic myomas (68.2\% of which were intramural, $29.6 \%$ were subserosal, and $2.2 \%$ were submucous) and palpated the uterus to target the benign tumors. ${ }^{18}$ After excision of what they thought were all of the myomas, the surgeons incorporated LUS into each procedure to determine how many myomas, if any, were left. LUS permitted the detection of 46 residual myomas, $95.66 \%$ of which were intramural and $4.34 \%$ were submucous.

In a retrospective study of 145 consecutive cases, Hanaf ${ }^{19}$ evaluated those factors that were associated with recurrence of myomas that were at least $2 \mathrm{~cm}$ in greatest diameter and that formed after open myomectomy. At surgery, $68 \%$ of the patients had intramural or intramuralsubserosal myomas, 4\% had submucous or submucousintramural myomas, 23\% had subserosal myomas, and 5\% had myomas in all locations. He reported that the cumulative probability of myoma recurrence increased after surgery to $62 \%$ at 5 years and was significantly greater in those women with $\geq 2$ myomas and in those women with a uterine size of $>10$ gestational weeks. Of the group of patients with reported recurrence, 52\% underwent subsequent surgical intervention. One of the limitations of the study was the lack of reporting on the locations of the myomas detected at follow-up.

Radosa et $\mathrm{al}^{20}$ also reported on myoma recurrence rate after laparoscopic myomectomy. Of the 443 myomas removed, 155 (35\%) were intramural, 177 (40\%) were subserosal, and 111 (25\%) were pedunculated. Of the 331 women who were initially studied, 107 were lost to follow-up and 224 were followed postoperatively to $108.23 \pm 24.41$ months. The recurrence rate at 60 months for intramural/subserous (FIGO type 2-6, Figure 1) myomas was $23.04 \%$. Two factors significantly increased the risk for recurrence of symptoms: age between 30 and 40 years and presence of multiple myomas at surgery. Increased risk of recurrence may also have been due to the surgeons not excising all myomas that were present at baseline. For example, in a randomized trial, Brucker et $\mathrm{al}^{21}$ reported excision of only $80.3 \%$ of myomas imaged on LUS, leaving in place intramural myomas that were located deep in the myometrium.

\section{Uterine artery embolization}

Uterine artery embolization (UAE) is an established minimally invasive, percutaneous, image-guided interventional technique involving the occlusion of one or both uterine arteries supplying blood to target myomas, including intramurals and intramurals abutting the endometrium, but not pedunculated myomas. Three studies of UAE indicated that the procedure is compromised by high rates of postprocedural complications and high rates $(28 \%-32 \%)$ of reintervention - including re-embolization, myomectomy, or hysterectomy - at 5 years postprocedure. ${ }^{22-24}$ Failure, defined as reintervention, after UAE appears to occur within the first 4 years of the procedure and reflects insufficient infarction. ${ }^{25,26}$ However, UAE provides a safe alternative to more surgically invasive procedures, such as myomectomy, in women who are poor surgical candidates, have fewer than six myomas, and do not desire future childbearing. ${ }^{27}$ 


\section{Magnetic resonance-guided focused ultrasound}

Magnetic resonance-guided focused ultrasound (MRgFUS) describes an approved device (Exablate; Insightec, Tirat Carmel, Israel) and method for noninvasive, nonsurgical ablation of leiomyomas, including intramurals, by focused ultrasound waves, which are guided to the target tissue by real-time three-dimensional MRI. Limitations of MRgFUS include the exclusion of women of large $(>115 \mathrm{~kg})$ habitus, the presence of bowel obstructing the target myoma, large fibroid volume (uterine size $>24$ weeks), and presence of intracavitary, nonenhancing, or heavily calcified myomas. ${ }^{28-30}$ The treatment is also contraindicated in women with abdominal scarring, metal implants, or claustrophobia. Froeling et $\mathrm{al}^{31}$ determined a $30 \%$ reintervention rate for MRgFUS after a median follow-up period of 13.3 months. Given the contraindications and costs, MRgFUS is an option to a limited subset of symptomatic patients.

\section{Radiofrequency volumetric thermal ablation}

Radiofrequency volumetric thermal ablation (RFVTA: the Acessa procedure; Halt Medical, Inc., Brentwood, CA, USA) is an outpatient, uterine-sparing, LUS-guided myoma ablation treatment that requires no myometrial or serosal suturing. LUS guides the surgeon's targeting and treatment of each myoma, regardless of its size or location within the uterus. Because laparoscopic and ultrasound visualization guides the treatment, even small $(<1 \mathrm{~cm})$ and otherwise hard-to-access intramural myomas can be ablated.

In a pivotal trial analyzing the reduction in menstrual blood loss in women with moderate-to-severe heavy menstrual bleeding (from $\geq 160$ to $\leq 500 \mathrm{~mL}$ as assessed by alkaline hematin) and who were treated with RFVTA, gynecologic surgeons treated 640 myomas. ${ }^{32}$ Calcified myomas and myomas that measured $0.7-9.7 \mathrm{~cm}$ in largest diameter were included, and the number of myomas treated per study participant ranged $1-29$. Of the 135 study subjects, only $48.4 \%$ had one or more submucous myomas in addition to myomas in other locations; yet, 135 women suffered from heavy menstrual bleeding. Of the 124 subjects followed to 12 months, a subset of 63 subjects had intramural myomas but no submucous myomas. This group greatly outnumbered the converse subset, that is, those with submucous myomas but no intramurals $(\mathrm{n}=10)$. The intramural group showed statistically and clinically significant reduction in menstrual blood loss: $-31.8 \%$ (95\% confidence interval, $-41.4 \%$ to $-22.2 \%$; $P<0.001)$ after ablation of their myomas. ${ }^{32-34}$ The cumulative reintervention rate at 3 years of follow-up post-RFVTA was $11 \% .{ }^{35}$ RFVTA has not been cleared by the US Food and
Drug Administration for the indication of infertility due to myomas or in women who desire future pregnancy.

\section{Conclusion}

The growing body of evidence reported in the literature supports the need to diagnose intramural myomas and manage them, in order to reduce the recurrence of symptoms and the need for further intervention. Rigorous prospective research should be undertaken to define clearly the negative influence that intramural myomas have on patients' well-being. Patients with symptomatic intramural myomas should be carefully evaluated and appropriately treated.

\section{Acknowledgment}

The authors received third-party editorial support, which was funded by Halt Medical, Inc.

\section{Disclosure}

The authors report no conflicts of interest in this work.

\section{References}

1. Munro MG, Critchley HO, Broder MS, Fraser IS, FIGO Working Group on Menstrual Disorders. FIGO classification system (PALMCOEIN) for causes of abnormal uterine bleeding in nongravid women of reproductive age. Int J Gynaecol Obstet. 2011;113(1):3-13.

2. Lee BB, Isaacson KB, Diamond MP. Radiofrequency volumetric thermal ablation of symptomatic uterine fibroids: the Acessa procedure. In: Al-Hendy A, Salama S, editors. Etiology, Clinical Manifestations, Evaluation and Management of Uterine Leiomyoma. New York: Nova Science; 2015:175-193.

3. Levine DJ, Berman JM, Harris M, Chudnoff SG, Whaley FS, Palmer SL. Sensitivity of myoma imaging using laparoscopic ultrasound compared with magnetic resonance imaging and transvaginal ultrasound. J Minim Invasive Gynecol. 2013;20(6):770-774.

4. Moshesh M, Peddada SD, Cooper T, Baird D. Intraobserver variability in fibroid size measurements. J Ultrasound Med. 2014;33:1217-1224.

5. Mavrelos D, Ben-Nagi J, Holland T, Hoo W, Naftalin J, Jurkovic D. The natural history of fibroids. Ultrasound Obstet Gynecol. 2010; 35:238-241.

6. Baird DD, Garrett TA, Laughlin SK, Davis B, Semelka RC, Peddada SD. Short-term change in growth of uterine leiomyoma: tumor growth spurts. Fertil Steril. 2011;95(1):242-246.

7. Yoshino O, Hayashi T, Osuga Y, et al. Decreased pregnancy rate is linked to abnormal uterine peristalsis caused by intramural fibroids. Hum Reprod. 2010;25(10):2475-2479.

8. Yan L, Ding L, Li C, Wang Y, Tang R, Chen ZJ. Effect of fibroids not distorting the endometrial cavity on the outcome of in vitro fertilization treatment: a retrospective cohort study. Fertil Steril. 2014;101(3): 716-721.

9. Lu N, Wang Y, Su YC, Sun YP, Guo YH. Effects of the distance between small intramural uterine fibroids and the endometrium on the pregnancy outcomes of in vitro fertilization-embryo transfer. Gynecol Obstet Invest. 2015;79(1):62-68.

10. Olive DL. The surgical treatment of fibroids for infertility. Semin Reprod Med. 2011;29(2):113-123.

11. Tinelli A, Mynbaev OA, Mettler L, et al. A combined ultrasound and histologic approach for analysis of uterine fibroid pseudocapsule thickness. Reprod Sci. 2014;21(9):1177-1186. 
12. Wei JJ, Zhang XM, Chiriboga L, Yee H, Perle MA, Mittal K. Spatial differences in biologic activity of large uterine leiomyomata. Fertil Steril. 2006;85(1):179-187.

13. Tinelli A, Malvasi A, Cavallotti C, et al. The management of fibroids based on immunohistochemical studies of their pseudocapsules. Expert Opin Ther Targets. 2011;15(11):1241-1247.

14. Falcone T, Parker WH. Surgical management of leiomyomas for fertility or uterine preservation. Obstet Gynecol. 2013;121(4):856-868.

15. Metwally M, Cheong YC, Horne AW. Surgical treatment of fibroids for subfertility. Cochrane Database Syst Rev. 2012;14;11:CD003857.

16. Pritts EA, Parker WH, Olive DL. Fibroids and infertility: an updated systematic review of the evidence. Fertil Steril. 2009;91(4): 1215-1223.

17. Carranza-Mamane B, Havelock J, Hemmings R, et al. The managemen of uterine fibroids in women with otherwise unexplained infertility. J Obstet Gynaecol Can. 2015;37(3):277-288.

18. Angioli R, Battista C, Terranova $\mathrm{C}$, et al. Intraoperative contact ultrasonography during open myomectomy for uterine fibroids. Fertil Steril. 2010;94(4):1487-1490.

19. Hanafi M. Predictors of leiomyoma recurrence after myomectomy. Obstet Gynecol. 2005;105(4):877-881.

20. Radosa MP, Owsianowski Z, Mothes A, et al. Long-term risk of fibroid recurrence after laparoscopic myomectomy. Eur J Obstet Gynecol Reprod Biol. 2014;180:35-39.

21. Brucker SY, Hahn M, Kraemer D, Taran FA, Isaacson KB, Krämer B. Laparoscopic radiofrequency volumetric thermal ablation of fibroids versus laparoscopic myomectomy. Int J Gynaecol Obstet. 2014;125(3): 261-265.

22. Watkinson A, Nicholson A. Uterine artery embolization to treat symptomatic uterine fibroids. BMJ. 2007;335(7622):720-722.

23. Moss JG, Cooper KG, Khaund A, et al. Randomised comparison of uterine artery embolisation (UAE) with surgical treatment in patients with symptomatic uterine fibroids (REST trial): 5-year results. BJOG. 2011 118(8):936-944

24. van der Kooij SM, Bipat S, Hehenkamp WJ, Ankum WM, Reekers JA. Uterine artery embolization versus surgery in the treatment of symptomatic fibroids: a systematic review and metaanalysis. Am JObstet Gynecol.2011; 205(4):317.e1-e18.
25. Scheurig-Muenkler C, Koesters C, Powerski MJ, Grieser C, Froeling V, Kroencke TJ. Clinical long-term outcome after uterine artery embolization: sustained symptom control and improvement of quality of life. J Vasc Interv Radiol. 2013;24(6):765-771.

26. Katsumori T, Kasahara T, Kin Y, Nozaki T. Infarction of uterine fibroids after embolization: relationship between postprocedural enhanced MRI findings and long-term clinical outcomes. Cardiovasc Intervent Radiol. 2011;31:66-72.

27. Mara M, Kubinova K. Embolization of uterine fibroids from the point of view of the gynecologist: pros and cons. Int J Womens Health. 2014; 6:623-629.

28. Clark NA, Mumford SL, Segars JH. Reproductive impact of MRIguided focused ultrasound surgery for fibroids: a systematic review of the evidence. Curr Opin Obstet Gynecol. 2014;26(3):151-161.

29. Fröling V, Kröncke TJ, Schreiter NF, et al. Technical eligibility for treatment of magnetic resonance-guided focused ultrasound surgery. Cardiovasc Intervent Radiol. 2014;37(2):445-450.

30. Behera MA, Leong M, Johnson L, Brown H. Eligibility and accessibility of magnetic resonance-guided focused ultrasound (MRgFUS) for the treatment of uterine leiomyomas. Fertil Steril. 2010;94(5): $1864-1868$.

31. Froeling V, Meckelburg K, Scheurig-Muenkler C, et al. Midterm results after uterine artery embolization versus MR-guided highintensity focused ultrasound treatment for symptomatic uterine fibroids. Cardiovasc Intervent Radiol. 2013;36(6):1508-1513.

32. Chudnoff SG, Berman JM, Levine DJ, Harris M, Guido RS, Banks E. Outpatient procedure for the treatment and relief of symptomatic uterine myomas. Obstet Gynecol. 2013;121:1075-1082.

33. Galen DI, Isaacson KB, Lee BB. Does menstrual bleeding decrease after ablation of intramural myomas? A retrospective study. J Minim Invasive Gynecol. 2013;20(6):830-835.

34. Lukes AS, Muse K, Richter HE, Moore KA, Patrick DL. Estimating meaningful reduction in menstrual blood loss for women with heavy menstrual bleeding. Curr Med Res Opin. 2010;26:2673-2678.

35. Berman JM, Guido RS, Garza Leal JG, Pemueller RR, Whaley FS, Chudnoff SG; Halt Study Group. Three-year outcome of the Halt trial: a prospective analysis of radiofrequency volumetric thermal ablation of myomas. J Minim Invasive Gynecol. 2014;21(5):767-774.
International Journal of Women's Health

\section{Publish your work in this journal}

The International Journal of Women's Health is an international, peerreviewed open-access journal publishing original research, reports, editorials, reviews and commentaries on all aspects of women's healthcare including gynecology, obstetrics, and breast cancer. The manuscript management system is completely online and includes

\section{Dovepress}

a very quick and fair peer-review system, which is all easy to use. Visit http://www.dovepress.com/testimonials.php to read real quotes from published authors. 